Title:

Mechanochemical synthesis of a mercury(II) metal-organic framework reveals a two-dimensional polymorph stabilized by weak interactions

\title{
Authors:
}

Isaiah R. Speight, ${ }^{\mathrm{a}}$ Igor Huskić, ${ }^{\mathrm{b}}$ Mihails Arhangelskis, ${ }^{\mathrm{b}}$ Hatem M. Titi, ${ }^{\mathrm{b}}$ Robin S. Stein, ${ }^{\mathrm{b}}$ Timothy P. Hanusa, ${ }^{a},{ }^{*}$ and Tomislav Friščić ${ }^{b}, *$

\section{Author address:}

a) Department of Chemistry, Vanderbilt University, Nashville, TN, 37235, USA; b) Department of Chemistry, McGill University, Montréal, QC, H3A 0B8, Canada

\section{Abstract:}

Solid-state mechanochemistry revealed a novel polymorph of the mercury(II) imidazolate framework, based on square-grid $(s q l)$ topology layers. Reaction monitoring and periodic density functional theory calculations show that the $s q l$-structure is of higher stability than the previously reported three-dimensional structure, with the unexpected stabilization of a lower dimensionality structure explained by contributions of weak interactions, which include short $\mathrm{C}-\mathrm{H} \cdots \mathrm{Hg}$ contacts.

\section{Main text:}

Metal-organic frameworks (MOFs) ${ }^{1}$ are one of the most active, prolific areas of materials chemistry, due to a modular design that permits rational incorporation of diverse metal ions and suitably functionalized organic linkers into functional solid-state structures. ${ }^{2}$ While a significant amount of effort has been put into developing materials with improved properties, ${ }^{3}$ fundamental and systematic studies of how the stability and topology of MOFs are affected by component choice and structure have remained less developed. ${ }^{4,5}$ Popular MOF designs have mostly focused on lighter main group (e.g. $\left.\mathrm{Li},{ }^{6} \mathrm{Mg},{ }^{7} \mathrm{Al}^{8}\right)$ and first row transition metals ${ }^{9-13}$ with the exception of NbOFFIVE, UiO- and NU-type MOFs based on $\mathrm{Nb}, \mathrm{Zr}$ or Hf. ${ }^{14-17}$ Although recent work started exploring the benefits of heavier elements $\mathrm{Ce}$, $\mathrm{Th}, \mathrm{U}$ or $\mathrm{Np}^{18-20}$ as framework nodes, properties and formation of MOFs with heavier, $6^{\text {th }}$ period members of the periodic table remains largely unexplored. ${ }^{21}$ Consequently, it is unknown to what extent such heavy elements are compatible with, and can bring novelty to, MOF designs. This is particularly relevant for topologically-flexible MOFs, such as zeolitic imidazolate frameworks (ZIFs) ${ }^{22}$ and other metal azolates, ${ }^{23}$ that are prone to polymorphism and can adopt a wide range of topologies depending on metal and linker choice. ${ }^{24}$ Mercury $\left(\right.$ as $\left.\mathrm{Hg}^{2+}\right)$ is particularly suitable for investigating the effect of heavy elements in ZIFs, as it is the heaviest accessible homologue of $\mathrm{Zn}^{2+}$, the most extensively used node in ZIF design. ${ }^{22-24}$ As ZIFs with $\mathrm{Cd}^{2+}$ have also been studied, ${ }^{25}$ using a $\mathrm{Hg}^{2+}$ node offers a unique opportunity to explore MOF formation across an entire series of homologous transition metals. While MOFs of $\mathrm{Hg}^{2+}$ are not likely to be of practical value, due to toxicity of mercury, we see studies of such materials as necessary to fully understand the scope and limitations of MOF designs.

To date, there has been one report of a mercury-based imidazolate framework, a diamondoid (dia) topology mercury(II) imidazolate $\mathrm{Hg}(\mathbf{I m})_{2}{ }^{26,27}$ The framework is isostructural to its cadmium analogue, both of which were made by precipitation from aqueous solution and structurally characterized from powder X-ray diffraction (PXRD) data (Fig. 1a) by Masciocchi et al. In 2006, Fernández-Bertrán et al. attempted the synthesis of $\operatorname{Hg}(\mathbf{I m})_{2}$ mechanochemically, ${ }^{28,29}$ 
from $\mathrm{HgO}$ and imidazole (HIm), and established that manual grinding led to partial formation of a material with hexagonal symmetry, distinct from dia- $\mathrm{Hg}(\mathbf{I m})_{2}$.
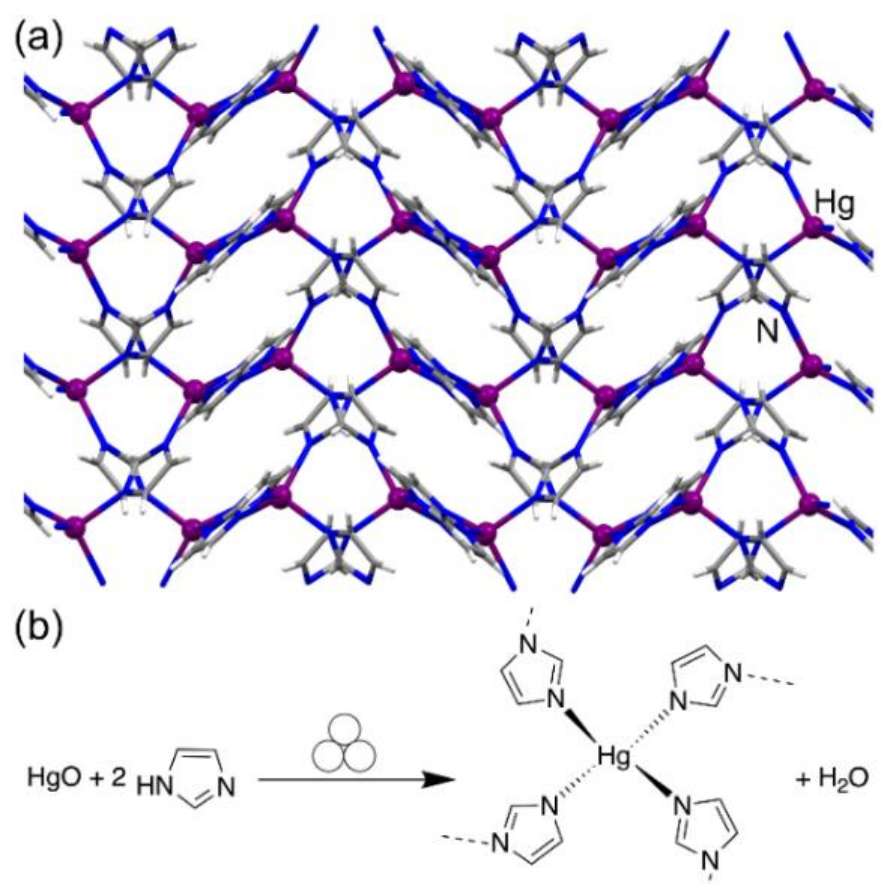

Fig. 1. (a) View of the crystal structure of dia- $\mathrm{Hg}(\mathbf{I m})_{2}$ and (b) herein explored mechanochemical reaction. The symbol for mechanochemical reaction conditions has been adopted from ref. 28 .

Intrigued by this potential difference in mechanochemical and solution-based routes to $\mathrm{Hg}(\mathbf{I m})_{2}$, we re-investigated the mechanochemical reaction by ball milling $\mathrm{HgO}$ and $\mathrm{HIm}$ in a respective 1:2 stoichiometric ratio (Fig. 1b) ${ }^{\ddagger}$ a methodology previously shown highly successful in making zinc ZIFs. ${ }^{24}$ Milling was performed in a $25 \mathrm{~mL}$ Teflon jar, using one $\mathrm{ZrO}_{2}$ ball (3.25 grams weight, see ESI). Chemical reaction upon milling was evident by change in color of the reaction mixture from orange (due to $\mathrm{HgO}$ ) to colorless. After $30 \mathrm{~min}$ milling, PXRD analysis revealed complete absence of Bragg reflections of reactants, indicating complete conversion (Fig. 2a). Unexpectedly, the product exhibited X-ray reflections that did not match either the dia$\mathrm{Hg}(\mathbf{I m})_{2}$ structure or the product of Fernández-Bertrán et al. 


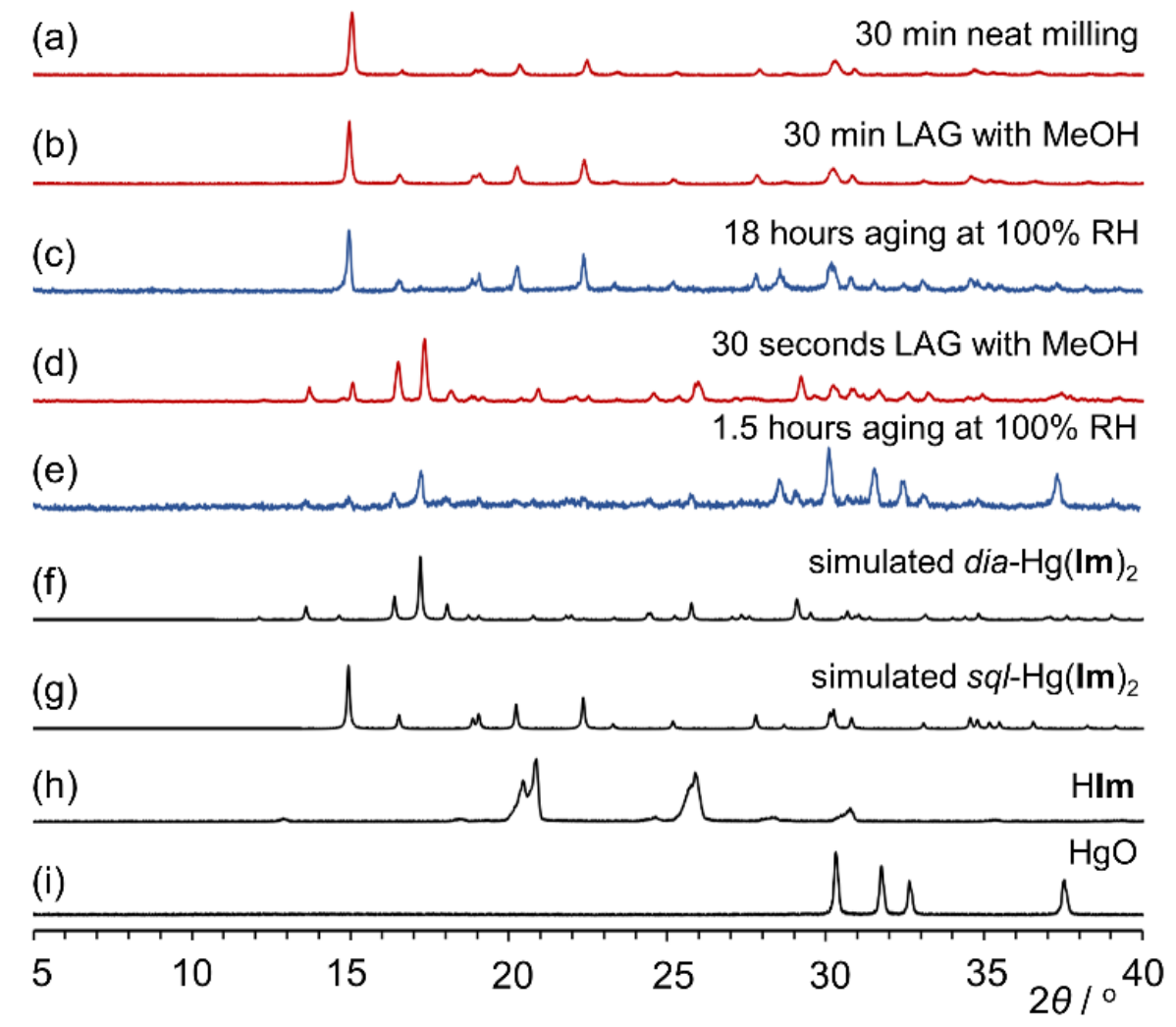

Fig. 2. Comparison of selected PXRD patterns for the reactions of $\mathrm{HgO}$ and HIm: (a) after $30 \mathrm{~min}$ neat milling; (b) after 30 min LAG with $\mathrm{MeOH}$; (c) after $18 \mathrm{~h}$ aging at 100\% RH; (d) after 30 seconds LAG with $\mathrm{MeOH}$; (e) after $1.5 \mathrm{~h}$ aging at $100 \% \mathrm{RH}$; (f) simulated for dia- $\mathrm{Hg}(\mathbf{I m})_{2}$ (CSD BAYPUN); (g) simulated for $s q l-\mathrm{Hg}(\mathbf{I m})_{2}$ and measured for: (h) $\mathrm{HIm}$; (i) $\mathrm{HgO}$.

The reaction was repeated by liquid-assisted grinding (LAG), ${ }^{30}$ a method in which the reaction progress is accelerated and directed by small amounts of a liquid. The outcome of the mechanochemical reaction did not change upon LAG with different liquids, including methanol (MeOH, Fig. 2b), N,N-dimethylformamide (DMF), acetonitrile (MeCN) or water (see ESI). Thermogravimetric analysis (TGA) of the product revealed no weight loss until the decomposition temperature of ca. $200{ }^{\circ} \mathrm{C}$, indicating that the material does not contain guest solvent.

Attempts to prepare the known dia- $\mathrm{Hg}(\mathbf{I m})_{2}$ by following the reported solution synthesis were unsuccessful, yielding a microcrystalline powder with a PXRD pattern identical to that of the mechanochemically made material. The PXRD pattern of mechanochemically prepared material was readily indexed to an orthorhombic unit cell in space group $P 2{ }_{1} 2{ }_{1} 2$, with $a=9.4089$ (4) $\AA$, $b=7.6414(3) \AA, c=5.3625(2) \AA$, and $V=385.55(3) \AA^{3}$. Structure solution and Rietveld refinement revealed a polymorph of $d i a-\mathrm{Hg}(\mathbf{I m})_{2}$, based on two-dimensional (2D) sheets of composition $\mathrm{Hg}(\mathbf{I m})_{2}$, with a square-grid $(s q l)$ topology (Fig. 3a,b). In contrast to reported dia- $\mathrm{Hg}(\mathbf{I m}) 2$, where $\mathrm{Hg}^{2+}$ adopts a roughly tetrahedral coordination with $\mathrm{N}-\mathrm{Hg}-\mathrm{N}$ angles from $98.3^{\circ}-117.7^{\circ}$ and $\mathrm{Hg}-\mathrm{N}$ bonds from $2.18 \AA-2.32 \AA$, the geometry of $\mathrm{Hg}^{2+}$ in $s q l-\mathrm{Hg}(\mathbf{I m})_{2}$ is highly distorted, best described as "see-saw" (Fig. 3c). 


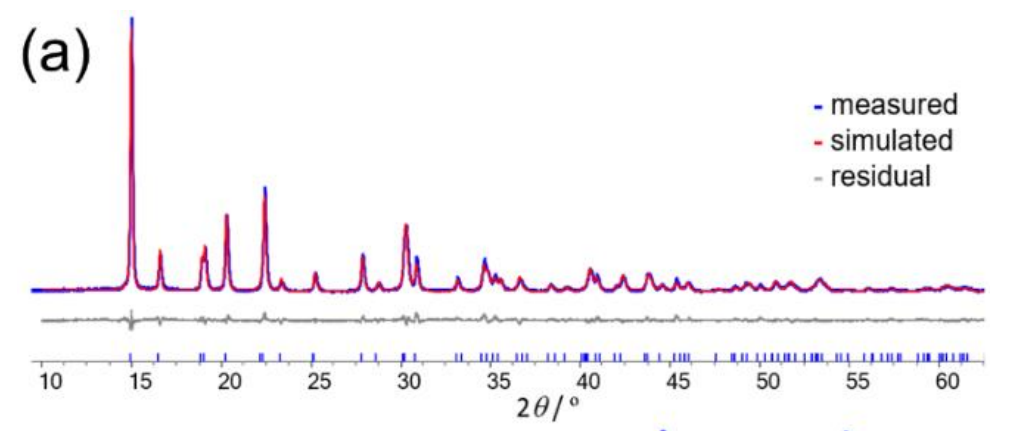

(b)
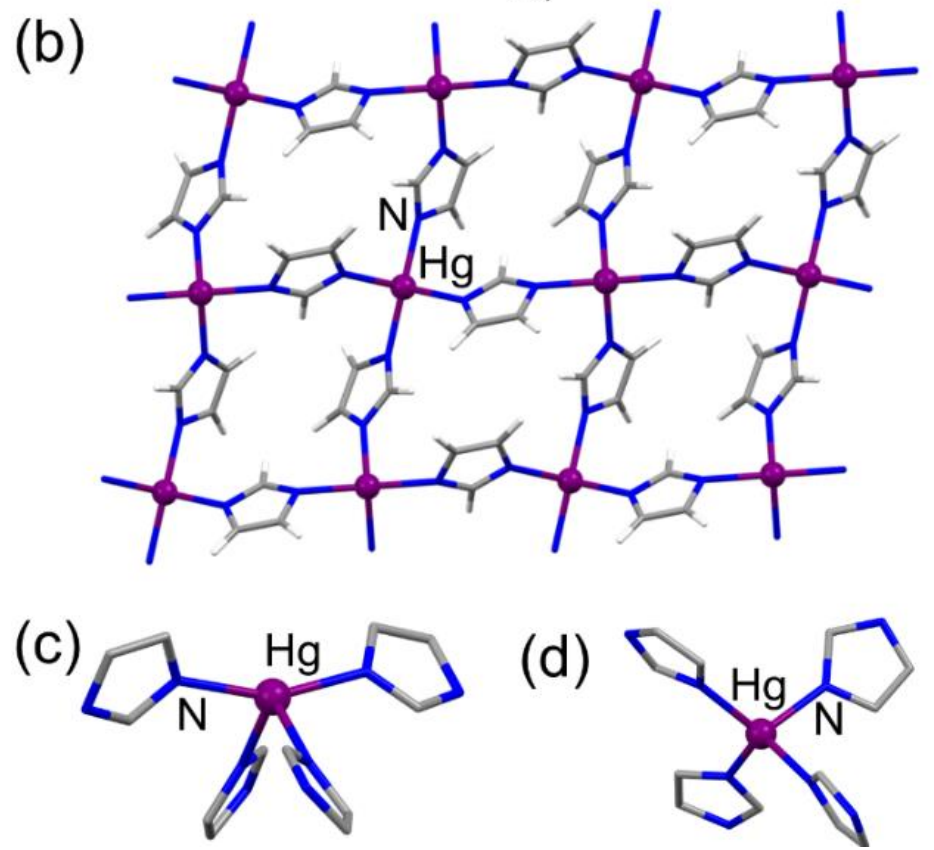

Fig. 3. (a) Final Rietveld refinement fit for the structure of $s q l-\mathrm{Hg}(\mathbf{I m})_{2}$ : experimental PXRD pattern is shown in blue, calculated pattern in red, and difference curve in grey. (b) view of a single layer of $s q l-\mathrm{Hg}(\mathbf{I m})_{2}$ along the crystallographic $c$-axis. Comparison of the coordination geometries of the metal node in: (c) $s q l-\mathrm{Hg}(\mathbf{I m})_{2}$ and (d) $d i a-\mathrm{Hg}(\mathbf{I m})_{2}$, with hydrogen atoms omitted for clarity.

The environment of each $\mathrm{Hg}^{2+}$ is defined by two shorter (2.18(2) $\AA$ ) $\mathrm{Hg}-\mathrm{N}$ bonds at an angle of 156.1(6) ${ }^{\circ}$, and a pair of longer ones (2.31(2) $\AA$ ), at an angle of 104.6(7) ${ }^{\circ}$ (Fig. 3d). In contrast to other reported sql-topology ZIFs $\mathrm{Ni}(\mathbf{I m})_{2}$ (CSD ALIDUU) $^{31}$ and zinc benzimidazolate (CSD KOLYAM) ${ }^{32}$ where neighboring layers arrange in an offset way, the sheets in $s q l-\mathrm{Hg}(\mathbf{I m})_{2}$ stack directly on top of each other (see ESI). The coordination of $\mathrm{Hg}^{2+}$ in $s q l-\mathrm{Hg}(\mathbf{I m})_{2}$ is consistent with its ${ }^{199} \mathrm{Hg}$ solid-state nuclear magnetic resonance (ssNMR) spectroscopy, revealing a powder pattern ${ }^{33}$ indicative of axial symmetry, very different from the one seen in $d i a-\mathrm{Cd}(\mathbf{I m})_{2}$ by ${ }^{113} \mathrm{Cd}$ ssNMR (see ESI).

We were surprised that all explored mechanochemical and solution-based experiments gave $s q l-\mathrm{Hg}(\mathbf{I m})_{2}$, without any evidence of $d i a-\mathrm{Hg}(\mathbf{I m})_{2}$ or the hexagonal phase reported by Fernández-Bertrán. ${ }^{29}$ In contrast, the dia-Cd(Im) $)_{2}$ phase reported by Masciocchi et al. was readily reproduced (see ESI). In an attempt to reproduce any of the reported $\mathrm{Hg}(\mathbf{I m})_{2}$ phases, we explored a milder synthetic route, by aging ${ }^{34}$ a 1:2 stoichiometric mixture of $\mathrm{HgO}$ and $\mathrm{HIm}$ at $100 \%$ relative humidity (RH). Real-time PXRD monitoring ${ }^{35}$ (Fig. 4a) revealed X-ray reflections of dia- $\mathrm{Hg}(\mathbf{I m})_{2}$ 
(Fig. 2e,c) and Rietveld analysis of the in situ data revealed that content of $\operatorname{dia}-\mathrm{Hg}(\mathbf{I m})_{2}$ increases for ca. 90 minutes, after which it diminishes along with the appearance of $s q l-\mathrm{Hg}(\mathbf{I m})_{2}(\mathbf{F i g}$. 4b). After $140 \mathrm{~min}$, the PXRD pattern exhibits only $s q l-\mathrm{Hg}(\mathbf{I m})_{2}$.

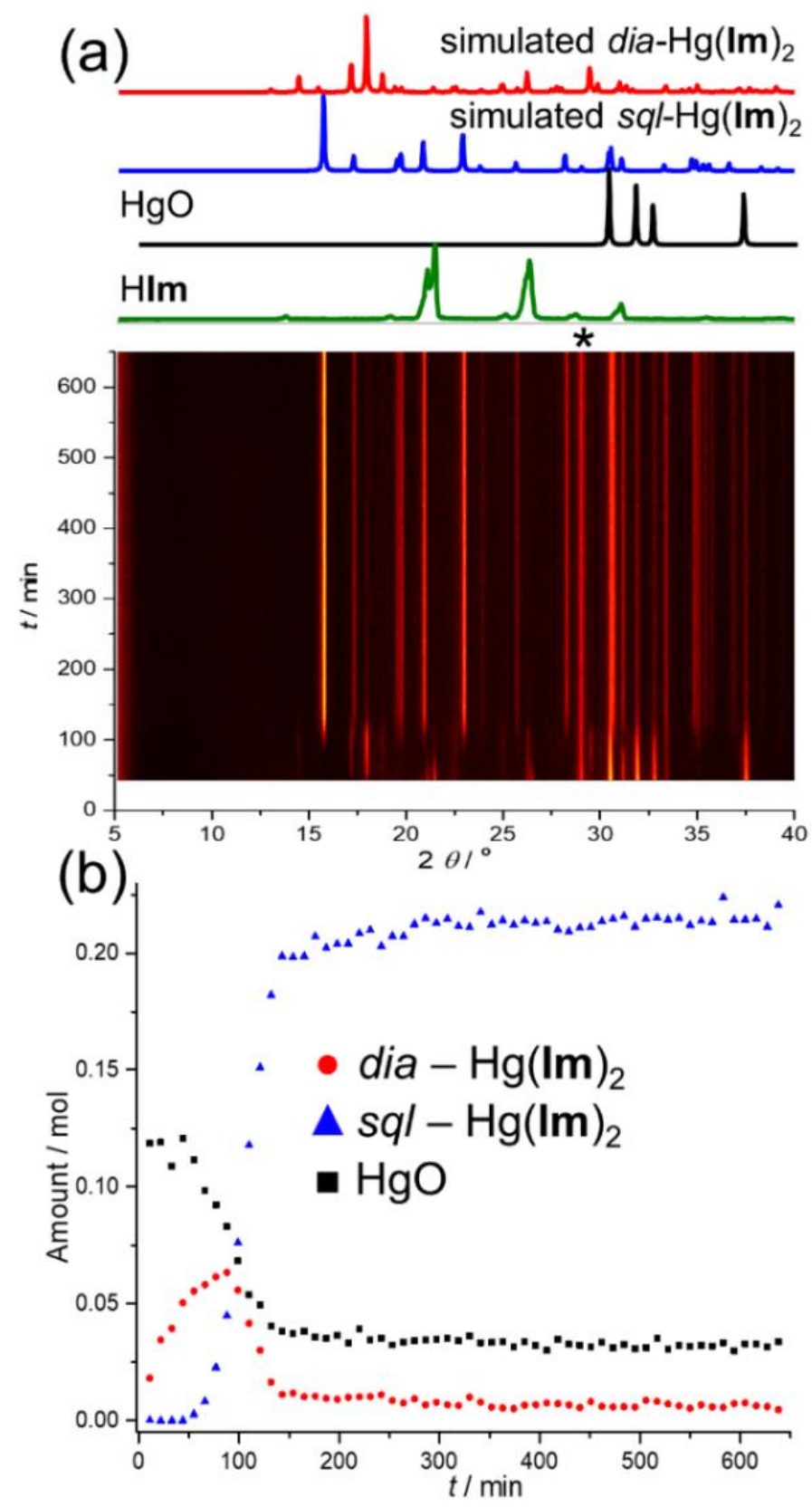

Fig. 4. Real-time monitoring of the aging reaction of $\mathrm{HgO}$ and $\mathrm{HIm}$ by PXRD: (a) time-resolved diffractogram, with diffraction patterns of selected phases shown on top, and Bragg reflection of $\mathrm{CeO}_{2}$ standard labeled with '*'; (b) reaction profile based on Rietveld fitting, demonstrating changes in amount of $\mathrm{HgO}$, dia- and $s q l-\mathrm{Hg}(\mathbf{I m})_{2}$. Quantitative kinetics analysis was hindered by preferred orientation in the static reaction mixture.

Initial, short-lived appearance of $d i a-H g(\mathbf{I m})_{2}$ in aging led us to explore the milling reaction of $\mathrm{HgO}$ and $\mathrm{HIm}$ at short reaction times. Indeed, PXRD analysis after 30 seconds LAG with $\mathrm{MeOH}$ 
revealed the appearance of $d i a-\mathrm{Hg}(\mathbf{I m})_{2}$ along with unreacted $\mathrm{HgO}$ and $\mathrm{HIm}$ (Fig. 2d). After 1 minute, the reaction mixture exhibits only reflections of $s q l-\mathrm{Hg}(\mathbf{I m})_{2}$.

Calculated densities of dia- and $s q l-\mathrm{Hg}(\mathbf{I m})_{2}$ are remarkably similar, preventing the deduction of relative stabilities. However, the dia- $\mathrm{Hg}(\mathbf{I m})_{2} \rightarrow s q l-\mathrm{Hg}(\mathbf{I m})_{2}$ transformation in aging and milling indicates that $s q$-form should be the thermodynamically more stable phase. ${ }^{24}$ This was validated by periodic density functional theory (DFT) calculations, performed in periodic DFT code CRYSTAL $17^{36}$ using the hybrid B3LYP ${ }^{37}$ functional combined with the Grimme D3 semiempirical dispersion correction, ${ }^{38}$ which showed that the $s q l$-form is $10.21 \mathrm{~kJ} \mathrm{~mol}^{-1}$ lower in energy than the dia-one. This contrasts $\mathrm{Zn}(\mathbf{I m})_{2}{ }^{39}$ and $\mathrm{Cd}(\mathbf{I m})_{2}$, whose most stable forms exhibit three-dimensional (3D) zni- and dia-topologies, respectively.

Intrigued by the unexpected difference between our study and previous reports on $\mathrm{Hg}(\mathbf{I m})_{2}$, we performed similar calculations for the reported dia-Cd(Im) 2 and the hypothetical $s q l-C d(I m)_{2}$ structure obtained by DFT optimization of a model obtained by replacing all $\mathrm{Hg}$ atoms in $s q \mathrm{l}$ $\mathrm{Hg}(\mathbf{I m})_{2}$ with $\mathrm{Cd}$. In this case, the two structures were found to have very similar energies, sql$\mathrm{Cd}(\mathrm{Im})_{2}$ being just $0.39 \mathrm{~kJ} \mathrm{~mol}^{-1}$ more stable. The improved stability of the dia-structure in $\mathrm{Cd}(\mathbf{I m})_{2}$ is consistent with numerous experimental observations of dia-Cd(Im) $)_{2}$

Stabilization of the 2D sql-structure in $\mathrm{Hg}(\mathbf{I m})_{2}$ compared to a more extensively connected and interpenetrated 3D dia-framework is unexpected and, we believe, associated to weak intermolecular interactions between layers. This is consistent with calculations of relative stabilities of dia- and $s q l-\mathrm{Hg}(\mathbf{I m})_{2}$ using the B3LYP functional uncorrected for dispersion. Under such conditions, stabilities of the two structures are inverted, with the dia-form becoming $7.81 \mathrm{~kJ}$ $\mathrm{mol}^{-1}$ more stable. Whereas the $s q l-\mathrm{Hg}(\mathbf{I m})_{2}$ structure reveals short contacts between neighboring layers, readily interpreted as $\mathrm{C}-\mathrm{H} \cdots \pi$ and $\pi \cdots \pi$ interactions, it also exhibits a short $\mathrm{H} \cdots \mathrm{Hg}$ contact of 3.26(3) $\AA$, not present in the dia-form. Most proposed van der Waals radii for $\mathrm{Hg}$ range from 2.00 to $2.53 \AA$, ${ }^{40}$ indicating that this contact might be up to $9 \%$ shorter than the sum of van der Waals radii of hydrogen $(1.25 \AA)$ and mercury. The unique appearance and energetic stability of $s q l-\mathrm{Hg}(\mathbf{I m})_{2}$, as opposed to its hypothetical $s q l-\mathrm{Cd}(\mathbf{I m})_{2}$ analogue, led us to perform Bader's quantum theory of atoms in molecules (QTAIM) ${ }^{41}$ analysis on the DFT-optimized structures, searching for bond critical points (BCPs) as evidence for structure-stabilizing interactions. The $s q l-\mathrm{Hg}(\mathbf{I m})_{2}$ and $\mathrm{Cd}(\mathbf{I m})_{2}$ structures display a very similar distribution of non-covalent BCPs (see ESI), with the exception of one BCP in the vicinity of the $\mathrm{Hg}$ atom. This critical point, unique to $s q l-\mathrm{Hg}(\mathbf{I m})_{2}$, reveals a moderate bonding interaction $\left(0.074\right.$ electrons $\left.\AA^{-3}\right)$ between the metal atom and the $\mathrm{C}-\mathrm{H}$ bond of an imidazolate linker from an adjacent metal-organic layer. This BCP is coincident with the experimentally noted short $\mathrm{H} \cdots \mathrm{Hg}$ contact, suggesting its importance for the overall stabilization of $s q l-\mathrm{Hg}(\mathbf{I m})_{2}$. While this $\mathrm{H} \cdots \mathrm{Hg}$ contact cannot be interpreted as a conventional bond, it is clearly stabilizing, tentatively corresponding to a weak agostic bond. ${ }^{42}$

In summary, a re-investigation of an early report of mechanochemical MOF formation has revealed a novel, layered polymorph of a so far unique mercury(II) imidazolate framework. Experiment and theory indicate that the layered polymorph is thermodynamically more stable than the previously reported interpenetrated dia-framework, evidently due to weak intermolecular forces that include previously unreported intermolecular agostic-like C-H $\cdots \mathrm{Hg}$ contacts. Such stabilization of a layered structure makes a striking contrast between $\mathrm{Hg}^{2+}$ and its congeners $\mathrm{Cd}^{2+}$ and $\mathrm{Zn}^{2+}$, whose imidazolates in their most stable form favor 3D frameworks, highlighting the potential for differences in MOF formation when using a heavy element compared to its lighter congeners. 


\section{Conflicts of interest}

There are no conflicts of interest to declare.

\section{Acknowledgements}

IRS and TPH acknowledge financial support by the NSF (CHE-1665327) and ACS-PRF (56027ND3); TF acknowledges support of NSERC (RGPIN-2017-06467, STPGP 521582-18). We thank Prof. R. W. Schurko (National MagLab) and Dr. V. Zorin (JEOL) for help setting up the BRAINCP/WURST-CPMG pulse sequences.

\section{Notes}

${ }^{\ddagger}$ Mercury compounds are highly toxic, and all operations must be conducted with great care and precaution.

\section{References:}

1 a) S. R. Batten, N. R. Champness, X.-M. Chen, J. Garcia-Martinez, S. Kitagawa, L. Öhrstrom, M. O'Keeffe, M. Paik Suh and J. Reedijk CrystEngComm 2012, 14, 3001. 2 a) B. Rungtaweevoranit, C. S. Diercks, M. J. Kalmutzki and O. M. Yaghi Faraday Discuss. 2017, 201, 9; b) P. Deria, J. E. Mondloch, O. Karagiaridi, W. Bury, J. T. Hupp and O. K. Farha Chem. Soc. Rev. 2014, 43, 5896.

3 a) H. Furukawa, N. Ko, Y. B. Go, N. Aratani, S. B. Choi, E. Choi, A. Ö. Yazaydin, R. Q. Snurr, M. O'Keeffe, J. Kim and O. M. Yaghi Science 2010, 329, 424; b) M. F. de Lange, K. J. F. M. Verouden, T. J. H. Vlugt, J. Gascon and F. Kapteijn Chem. Rev. 2015, 115, 12205. 4 a) M. E. Schweinefuß, S. Springer, I. A. Baburin, T. Hikov, K. Huber, S. Leoni and M. Wiebcke Dalton Trans. 2014, 43, 3528; b) F.-X. Coudert, A. H. Fuchs Coord. Chem. Rev. 2016, 307, 211.

5 a) M. Arhangelskis, A. D. Katsenis, A. J. Morris and T. Friščić Chem. Sci. 2018, 9, 3367;

b) H. M. Titi, M. Arhangelskis, A. D. Katsenis, C. Mottillo, G. Ayoub, J.-L. Do, A. M. Fidelli, R. D. Rogers and T. Friščić Chem. Mater. 2019, 31, 4882.

6 J. Zhang, T. Wu, C. Zhou, S. Chen, P. Feng and X. Bu Angew. Chem. Int. Ed. 2009, 48, 2542.

7 D. Gygi, E. D. Bloch, J. A. Mason, M. R. Hudson, M. I. Gonzalez, R. L. Siegelman, T. A. Darwish, W. L. Queen, C. M. Brown and J. R. Long Chem. Mater. 2016, 28, 1128.

8 T. Loiseau, C. Serre, C. Huguenard, G. Fink, F. Taulelle, M. Henry, H. Bataille and G. Férey Chem. Eur. J. 2004, 10, 1373.

9 G. Férey, C. Mellot-Draznieks, C. Serre, F. Millange, J. Dutour, S. Surblé and I. Marhiolaki Science 2005, 309, 2040.

10 J. López-Cabrelles, J. Romero, G. Abellán, M. Giménez-Marqués, M. Polomino, S. Valencia, F. Rey and G. Mínguez Espallargas J. Am. Chem. Soc. 2019, 141, 7173.

11 H. Deng, S. Grunder, K. E. Cordova, C. Valente, H. Furukawa, M. Hmadeh, F. Gándara, A. C. Whalley, Z. Liu, S. Asahina, H. Kazumori, M. O'Keeffe, O. Terasaki, J. F. Stoddart and O. M. Yaghi Science 2012, 336, 1018.

12 G. Zhong, D. Liu and J. Zhang J. Mat. Chem. A 2018, 6, 1887.

13 S. S.-Y. Chui, S. M.-F. Lo, J. P. H. Charmant, A. G. Orpen and I. D. Williams Science 1999, 283, 1148.

14 P. M. Bhatt, Y. Belmabkhout, A. Cadiau, K. Adil, O. Shekhah. A. Shkurenko, L. J. Barbour and M. Eddaoudi J. Am. Chem. Soc. 2016, 138, 9301. 
15 J. Hafizovic-Cavka, S. Jakobsen, U. Olsbye, N. Guillou, C. Lamberti, S. Bordiga and K. P. Lillerud, J. Am. Chem. Soc. 2008, 130, 13850.

16 T. C. Wang, N. A. Vermeulen, I. S. Kim, A. B. F. Martinson, J. F. Stoddart, J. T. Hupp, O. K. Farha Nat. Prot. 2016, 11, 149.

17 M. J. Cliffe, W. Wan, X. Zou, P. A. Chater, A. K. Kleppe, M. G. Tucker, H. Wilhelm, N. P. Funnell, F.-X. Coudert and A. L. Goodwin Nat. Commun. 2014, 5:4176.

18 M. Lammert, M. T. Wharmby, S. Smolders, B. Bueken, A. Lieb, K. A. Lomachenko, D. De Vos and N. Stock Chem. Commun. 2015, 51, 12578.

19 a) K. P. Carter, J. A. Ridenour, M. Kalaj and C. L. Cahill Chem. Eur. J. 2019, 25, 7114;

b) E. A. Dolgopolova, A. M. Rice and N. B. Shustova Chem. Commun. 2018, 54, 6472. 20 a) C. Falaise, C. Volkringer, J.-F. Vigier, N. Henry, A. Beaurain and T. Loiseau Chem. Eur. J. 2013, 19, 5324; b) S. E. Gilson, P. Li, J. E. S. Szymanowski, J. White, D. Ray, L. Gagliardi, O. K. Farha and P. C. Burns J. Am. Chem. Soc. 2019, 141, 11842.

21 a) Y. Zhang, B. E. G. Lucier, S. M. McKenzie, M. Arhangelskis, A. J. Morris, T. Friščić, J. W. Reid, V. V. Terskikh, M. Chen and Y. Huang ACS Appl. Mater. Int. 2018, 10, 28582;

b) L. Robison, L. Zhang, R. J. Drout, P. Li, C. R. Haney, A. Brikha, H. Noh, B. L. Mehdi, N. D. Browning, V. P. Dravid, Q. Cui, T. Islamoglu and O. K. Farha ACS Appl. Biomat. 2019, 2, 1197.

22 K. S. Park, Z. Ni, A. P. Côte, J. Y. Choi, R. Huang, F. J. Uribe-Romo, H. K. Chae, M. O'Keeffe and O. M. Yaghi Proc. Natl. Acad. Sci. U.S.A. 2006, 103, 10186. 23 J.-P. Zhang, Y.-B. Zhang, J.-B. Lin and X.-M. Chen Chem. Rev. 2012, 112, 1001. 24 a) Z. Akimbekov, A. D. Katsenis, G. P. Nagabushana, G. Ayoub, M. Arhangelskis, A. J. Morris, T. Friščić and A. Navrotsky J. Am. Chem. Soc. 2017, 139, 7952; b) M. Arhangelskis, A. D. Katsenis, N. Novendra, Z. Akimbekov, D. Gandrath, J. M. Marrett, G. Ayoub, A. J. Morris, O. K. Farha, T. Friščić and A. Navrotsky Chem. Mater. 2019, 31, 3777.

25 a) Y.-Q. Tian, S.-Y. Yao, D. Gu, K.-H. Cui, D.-W. Guo, G. Zhang, Z.-X. Chen and D.-Y. Zhao, Chem. Eur. J. 2010, 16, 1137; b) S.-Y. Yao and Y.-Q. Tian CrystEngComm 2010, 12, 697.

26 N. Masciocchi, G. A. Ardizzoia, S. Brenna, F. Castelli, S. Galli, A. Maspero and A. Sironi, Chem. Commun. 2003, 2018.

27 A search of the Cambridge Structural Database (CSD version 5.40, Feb 2019 update) also reveals two $\mathrm{Hg}$ (II) tetrazolate frameworks, and a pyrazolate: a) D.-S. Liu, Y. Sui, G.-M. Ye, H.-y. Wang, J.-Q. Liu and W.-T. Chen J. Solid State Chem. 2018, 263, 182; b) J. Xianglin, S. Meicheng, H. Haochuan, W. Jinming and Z. Yu Chin. Chem. Bull. 1982, 336; c) N. Masciocchi, G. A. Ardizzoia, A. Maspero, G. LaMonica and A. Sironi Inorg. Chem. 1999, 38, 3657.

28 N. R. Rightmire, T. P. Hanusa Dalton Trans. 2016, 45, 2352.

29 J. F. Fernández-Bertran, M. P. Hernández, E. Reguera, H. Yee-Madeira, J. Rodriguez, A. Paneque and J. C. Llopiz J. Phys. Chem. Sol. 2006, 67, 1612.

30 T. Friščić, C. Mottillo and H. M. Titi Angew. Chem. Int. Ed. 2019, DOI:10.1002/anie.201906755

31 N. Masciocchi, F. Castelli, P. M. Forster, M. M. Tafoya and A. K. Cheetham Inorg. Chem. 2003, 42, 6147.

32 Q.-F. Yang, X.-B. Cui, J.-H. Yu, J. Lu, X.-Y. Yu, X. Zhang, J.-Q. Xu, Q. Hou and T.-G. Wang CrystEngComm 2008, 10, 1531. 
33 K. J. Harris, A. Lupulescu, B. E. G. Lucier, L. Frydman and R. W. Schurko, J. Magn. Reson. 2012, 224, 38.

34 C. Mottillo and T. Friščić Molecules 2017, 22, 144.

35 I. Huskić, J.-C. Christopherson, K. Užarević and T. Friščić Chem. Commun. 2016, 52, 5120 .

36 R. Dovesi, A. Erba, R. Orlando, C. M. Zicovich-Wilson, B. Civalleri, L. Maschio, M. Rérat, S. Casassa, J. Baima, S. Salustro and B. Kirtman, Wiley Interdiscip. Rev. Comput. Mol. Sci., 2018, 8, e1360

37 a) A. D. Becke, J. Chem. Phys., 1993, 98, 5648; b) C. Lee, W. Yang and R. G. Parr, Phs. Rev. B, 1988, 37, 785

38 S. Grimme, J. Antony, S. Ehrlich and H. Krieg, J. Chem. Phys., 2010, 132, 154104. 39 I. A. Baburin, S. Leoni and G. Seifert J. Phys. Chem. B 2008, 112, 9437.

40 a) S.-Z. Hu, Z.-H. Zhou and B. E. Robertson Z. Kristallogr. 2009, 224, 375; b) S. Alvarez Dalton Trans. 2013, 42, 8617.

41 R. F. W. Bader, J. Phys. Chem. A, 1998, 102, 7314.

42 Y.-C. Chen, J.-Y. Tung, T.-K. Liu, W.-J. Tsai, H.-Y. Lin, Y.-C. Chang and J.-H. Chen Dalton Trans. 2018, 47, 14774. 